\title{
Initial biochar effects on plant productivity derive from $\mathrm{N}$ fertilization
}

by Jeffery, S., Memelink, I., Hodgson, E., Jones, S., van de Voorde, T.F.J., Bezemers, M., Mommer, L. and van Groenigen, J.W.

Copyright, Publisher and Additional Information: This is the author accepted manuscript. The final published version (version of record) is available online via Springer Please refer to any applicable terms of use of the publisher.

DOI: 10.1007/s11104-016-3171-z 
Number of text pages: 27

Number of Tables: 2

Number of Figures: 5

Short running title: Biochar increases plant productivity by $\mathrm{N}$ fertilization

Corresponding Author:

Dr. Simon Jeffery

Crop and Environment Sciences Department

Newport

Shropshire

TF10 8NB

Email: sjeffery@harper-adams.ac.uk 
Initial biochar effects on plant productivity derive from $\mathrm{N}$ fertilization

Simon Jeffery ${ }^{1 *}$, Ilse Memelink² ${ }^{2}$ Edward Hodgson ${ }^{3}$, Sian Jones ${ }^{3}$, Tess F.J. van de Voorde ${ }^{4}$, T. Martijn Bezemer $^{5,6}$, Liesje Mommer ${ }^{4}$, Jan Willem van Groenigen².

1 Department of Crop and Environment Sciences, Harper Adams University, Newport, TF10 8NB, United Kingdom.

2 Department of Soil Quality, Wageningen University, Wageningen, 6700AA, The Netherlands.

3 Low Carbon Energy and Environment Network, Institute of Biological Environmental and Rural Sciences, Aberystwyth University, Gogerddan, Aberystwyth, Ceredigion, SY23 3EB, Wales.

4 Plant Ecology and Nature Conservation Group, Wageningen University, P.O. Box 47, 6700AA

Wageningen, The Netherlands .

5 Department of Terrestrial Ecology, Netherlands Institute of Ecology (NIOO-KNAW), P.O. Box 50, 6700AB Wageningen, The Netherlands.

6 Institute of Biology, Section Plant Ecology and Phytochemistry, Leiden University, PO Box 9505, 2300 RA Leiden, The Netherlands.

Key words:

Pyrolysis; Organic amendment; Stable isotopes; C dynamics; N immobilisation; greenhouse gases 


\section{Abstract}

2 Background and Aim Biochar application to soil is widely claimed to increase plant productivity.

3 However, the underlying mechanisms are still not conclusively described. Here, we aim to elucidate

4 these mechanisms using stable isotope probing.

5 Methods We conducted two experiments with uniquely double-labelled $\left({ }^{15} \mathrm{~N}\right.$ and $\left.{ }^{13} \mathrm{C}\right)$ biochar and its

6 feedstock (residue), applied separately at $15 \mathrm{Mg} \mathrm{ha}^{-1}$. Both experiments contained three treatments:

7 biochar amendment (Biochar), unpyrolysed residue amendment (Residue) and a no addition control

8 (Control). Experiment I was a 119 day pot experiment seeded with Lolium perenne. Experiment II was

9 a 71 day incubation experiment without plants in which $\mathrm{CO}_{2}$ and $\mathrm{N}_{2} \mathrm{O}$ fluxes were measured.

Results Both Biochar and Residue significantly increased aboveground productivity compared to Control (140\% and $160 \%$, respectively). Initial N immobilisation was stimulated in Residue, whereas not in Biochar. ${ }^{13} \mathrm{C}-\mathrm{CO}_{2}$ analysis confirmed that biochar was significantly more recalcitrant than residue. ${ }^{15} \mathrm{~N}$ analysis showed that $2 \%$ and $0.3 \%$ of grass $\mathrm{N}$ was derived from the amended material in Residue and Biochar, respectively.

Conclusions Our results suggest that biochar-induced yield increases derive from a combination of reduced $\mathrm{N}$ immobilization and a moderate $\mathrm{N}$ fertilization effect. Although in the short term biochar might offer benefits compared to residue incorporation, it is unlikely that biochar yield gains will be sustainable for the decades to centuries that biochar $\mathrm{C}$ can be expected to reside in soil. 
Interest in biochar has grown considerably since the term was first coined in 2000 (Karaosmanoğlu et al. 2000) and subsequently recognized as a soil conditioner (Lehmann et al. 2006). Biochar is produced through the heating of biomass (feedstock) to temperatures generally exceeding $350{ }^{\circ} \mathrm{C}$, in low to zero oxygen environments (Shackley et al. 2013). It has been repeatedly demonstrated that biochar application to soil can bring benefits in terms of crop yield increases (Jeffery et al. 2011; Liu et al. 2013; Jeffery et al. 2015a). Other studies have shown that it can reduce greenhouse gas (GHG) emissions (Cayuela et al. 2014; Maestrini et al. 2014; Sagrilo et al. 2015), and increase carbon (C) storage in soils (Gurwick et al. 2013), thereby potentially mitigating climate change (Woolf et al. 2010). However, negative effects have also been reported (Mukherjee and Lal 2014), including negative effects on crop yields (Singla et al. 2014; Nelissen et al. 2015).

Despite the growing body of research, the mechanisms behind observed effects following biochar application to soil remain poorly understood. This is largely due to a lack of appropriate experimental controls, as well as the systems-level research approach generally adopted (Jeffery et al. 2015b). A mechanistic understanding of biochar impacts is vital to allow effective predictions regarding biochar soil amendment and its consequences for soil-based ecosystem services including crop productivity. This will aid maximisation of the potential benefits of biochar application to soil while concurrently minimising trade-offs (Crombie et al. 2015; Jeffery et al. 2015b)

One potential mechanism underlying crop yield increases following biochar application is a fertilization effect. This has been shown for potassium (K) which is present in the ash component of biochar (Mia et al. 2014; Oram et al. 2014). Besides providing nutrients, biochar may also affect nutrient cycling and leaching of nutrients in indirect ways (Spokas et al. 2012; Clough et al. 2013). Two extensive reviews on the effects of biochar application to soil on $\mathrm{N}$ dynamics (Clough et al. 2013; Cayuela et al. 2014) suggest that one of the main mechanisms is adsorption leading to reduced $\mathrm{N}$ 
leaching. This is particularly true for high temperature $\left(>600{ }^{\circ} \mathrm{C}\right)$ biochars and for $\mathrm{NO}_{3}$. Conversely, $\mathrm{NH}_{4}{ }^{+}$retention appears more dependent on the type of feedstock than on pyrolysis temperature (Karaosmanoğlu et al. 2000). Biochar has also been shown to interact with denitrification through its function as an electron shuttle during redox reactions (Cayuela et al. 2013).

Few studies have aimed to investigate the bioavailability of $\mathrm{N}$ from biochars beyond quantifying hydrolysable organic N (Clough et al. 2013). Meta-analyses have not found significant differences in yield effects with biochar applied alone or in combinations with fertilizers, either organic or inorganic (Jeffery et al. 2011; Liu et al. 2013). On an individual study level there is some evidence that biochar application to soil can decrease the apparent nitrogen recovery (ANR) of plants (Nelissen et al. 2015). The suggested mechanism for this effect was $\mathrm{N}$ immobilisation. However, this effect is dependent on pyrolysis conditions and type of feedstock, as they lead to different propensities for labile compounds to remain on the surface of biochar particles post production (Cornelissen et al. 2005). The application of stable isotope ${ }^{15} \mathrm{~N}$ probing provides a means of quantifying the relative and absolute uptake of $\mathrm{N}$ from materials amended to soil (Bedard-Haughn et al. 2003), such as biochar, and so quantifying bioavailability of this key plant nutrient.

Besides interactions with mineral $\mathrm{N}$, biochar application to soil has also been shown to interact with soil organic matter (SOM). These interactions include accelerated turnover of SOM (i.e. positive priming; Wardle et al. 1999), reduced turnover of SOM (i.e. negative priming; Zimmerman et al. 2010) and no effect (Sagrilo et al. 2015). The application of ${ }^{13} \mathrm{C}$ labelled biochar can provide insights into the contribution of $\mathrm{C}$ pools to $\mathrm{CO}_{2}$ fluxes as well as into immobilization / decomposition effects related to $\mathrm{N}$ availability (Boschker et al. 1998). Further, through combination with ${ }^{13} \mathrm{C}$ phospholipid fatty acid (PLFA) analysis, the main microbial groups able to utilise substrates can be identified, potentially providing insights into microbial-based mechanisms (Boschker et al. 1998). 
Here, we utilise a double-labelled $\left({ }^{13} \mathrm{C}\right.$ and $\left.{ }^{15} \mathrm{~N}\right)$ biochar and its feedstock to investigate the effects of biochar application to soil on $\mathrm{N}$ availability and relate $\mathrm{C}$ and GHG dynamics. Work conducted here was focussed on grasslands, which have been largely overlooked in biochar research despite suggestions that application to grassland will be required to maximise the GHG offsetting capabilities of biochar (Woolf et al. 2010). Through the use of unpyrolysed feedstock as a positive control we aim to elucidate biochar effects per se, i.e. those that are beyond what would have been observed with the application of the feedstock alone. To do so we will test the hypothesis that plant productivity increases following biochar application to soil derive from a fertility effect. If accepted, this suggests that yield effects may not last for as long as the residence time of $C$ in soil, often estimated to be in the range of decades to centuries (Lehmann et al. 2006). Rather, they will last until available nutrients are utilised and become limiting locally once more.

\section{Materials and Methods}

This project was focussed on grasslands and so grassland species were used both for the feedstock and for the plants grown. Plantago lanceolate is a common plant in grasslands and is fast growing with broad leaves meaning it produces biomass relatively quickly. It was also applied in unpyrolysed form as a positive control (hereafter Residue). The feedstock was isotopically enriched with ${ }^{13} \mathrm{C}$ and

${ }^{15} \mathrm{~N}$ as described below. These materials were used in two experiments that used the same homogenised soil: a greenhouse experiment with Lolium perenne grown in pots (Experiment I) and an incubation experiment without plants in a climate controlled room to quantify GHG fluxes (Experiment II).

\section{Isotopically labelling biomass}


Biomass (Plantago lanceolata) was grown in a growth chamber in a vermiculite substrate. Key characteristics can be found in Table 1. During the growth period it was pulse-labelled with ${ }^{13} \mathrm{C}-\mathrm{CO}_{2}$, following the method of Bromand et al. (2001). Biomass was labelled with ${ }^{15} \mathrm{~N}$ through fertilization with $\mathrm{Ca}\left({ }^{15} \mathrm{NO}_{3}\right)_{2}$ added to a fertilizer solution applied to the vermiculite daily to achieve an enrichment approx. $58 \%$ atom. Aboveground biomass of Plantago lanceolata was harvested twice, at pre-flowering stage. This was done to ensure only leaves were included and no stems or flowers, thereby reducing the heterogeneity of the feedstock. Harvests were performed by cutting plants back to approx. $2 \mathrm{~cm}$ above the surface of the vermiculite, after 5 weeks for the first harvest and 7 weeks for the second. After harvest, biomass was oven-dried at $60{ }^{\circ} \mathrm{C}$ for 24 hours. The dried biomass of both harvests was ground to $2 \mathrm{~mm}$, combined and mixed. A sub-sample of approximately $70 \%$ of the biomass was pyrolysed to produce biochar (pyrolysis under $\mathrm{N}_{2}$, max temp $400{ }^{\circ} \mathrm{C}$, residence time 30 min; Aberystwyth University, Wales). The remaining $30 \%$ of the biomass was used for the Residue treatments described below. Analyses of biochar and residue from which it was produced were performed using a Pyris 1 thermogravimetric analyser (TGA) (Perkin-Elmer, Massachusetts, USA; Hodgson et al. 2011). In short, samples were pyrolysed under nitrogen at a flow rate of $20 \mathrm{~mL} \mathrm{~min}^{-1}$ using the following temperature program: Heated from 40 to $105{ }^{\circ} \mathrm{C}$ at 10 ${ }^{\circ} \mathrm{C} \mathrm{min}-1$; held at $105{ }^{\circ} \mathrm{C}$ for $10 \mathrm{~min}$; heated from 105 to $905^{\circ} \mathrm{C}$ at 10,25 , and $100{ }^{\circ} \mathrm{C} \mathrm{min}^{-1}$; held at 905 ${ }^{\circ} \mathrm{C}$ for $15 \mathrm{~min}$; cooled from 905 to $105{ }^{\circ} \mathrm{C}$ at $25{ }^{\circ} \mathrm{C} \mathrm{min}-1$. A proximate analysis was performed on the TGA data to calculate the relative proportions volatiles, fixed carbon and ash (wt. \%). Volatiles were calculated from mass loss occurring between 105 and $550{ }^{\circ} \mathrm{C}$, fixed carbon from $550^{\circ} \mathrm{C}$ to $900{ }^{\circ} \mathrm{C}$ and ash as the remaining material after heating. An elemental analysis was used for analysis of $\mathrm{H}: \mathrm{C}_{\mathrm{org}}$ which is reported as a molar mass ratio.

For the $\mathrm{C}: \mathrm{N}$ ratio, ${ }^{13} \mathrm{C}$ and ${ }^{15} \mathrm{~N}$ content analysis, three replicates $(2 \mathrm{mg})$ of both residue and biochar were placed into individual tin capsules and analysed using a PDZ Europa ANCA-GSL elemental analyser interfaced to a PDZ Europa 20-20 isotope ratio mass spectrometer (Sercon Ltd.; Cheshire, 
UK) at The Stable Isotope Facility of UC Davis, USA. Key characteristics of both the residue and the biochar can be found in Table 1.

\section{Soil}

Topsoil (top $10 \mathrm{~cm}$ ) was collected from a nature restoration grassland area on the Veluwe, in Gelderland, Netherlands (52.059826N, 5.751354E) on $11^{\text {th }}$ March 2014. The site is located on an ice pushed ridge formed during the Saalien Ice Age. The soil is characterised as a "holtpodzol" on coarse sand (gY30; Stiboka, 1975: map 40 W). The area was used as arable field until 1995 and had last been used to grow maize in 1995. Previous to that cropping had included cycles of sugar beet, potatoes and oats. Collected soil was sieved to pass $4 \mathrm{~mm}$ and thoroughly mixed to ensure homogenisation. After homogenisation the soil was split into two parts to be used for Experiments I and II. Soil characteristics were determined in Mia et al. (2014) and Oram et al. (2014). Further information on methods for soil analysis can be found in those studies. Key soil characteristics are presented in Table 2.

\section{Experiment I - Plant growth}

Soil for each treatment was amended with biochar and residue each at a rate equivalent to $15 \mathrm{t} \mathrm{ha}{ }^{-1}$, incorporated into the top $10 \mathrm{~cm}$ of soil produced with five replicates. Soil was packed into $9.5 \mathrm{~cm}$ diameter $0.5 \mathrm{~L}$ polypropylene pots ( $505 \mathrm{~g}$ dry weight $(\mathrm{dw}$ ) of soil, packed to a dry bulk density of $1.2 \mathrm{~g}$ $\mathrm{cm}^{-3}$ ). The control consisted of unamended soil packed to the same bulk density. A 1-cm deep layer consisting of $94 \mathrm{~g}$ of soil (i.e. without biochar or feedstock) was added to the surface of pots to function as a germination layer as biochar has previously been shown to occasionally inhibit germination. All treatments were replicated five times, totalling 15 pots, set up in a completely randomised design. The experiment was performed in a greenhouse (average $60 \%$ relative humidity; average temperature $21^{\circ} \mathrm{C}$ ) of Wageningen University, The Netherlands. 
In each pot, 10 wild type Lolium perenne (diploid) seeds were sown at a seeding rate equivalent to 27

$138 \mathrm{~kg} \mathrm{ha}^{-1}$. Owing to reduced germination in some pots, pots were reseeded after a week in order to 139 achieve 10 plants per pot.

140 After germination, pots were fertilized at rates equivalent to $30 \mathrm{~kg} \mathrm{P} \mathrm{ha}^{-1}$ and $140 \mathrm{~kg} \mathrm{~K} \mathrm{ha}^{-1}\left(\mathrm{KH}_{2} \mathrm{PO}_{4}\right.$

141 and $\mathrm{K}_{2} \mathrm{SO}_{4}$ ). Applications of fertilizer were spread over four days to minimise the risk of burning the

142 seedlings. No $\mathrm{N}$ fertilizer was added to any of the pots. Water was added following fertilisation to

143 bring all the pots to $60 \%$ water-filled pore space (WFPS) and to ensure that the fertilizer moved

144 deeper into the soil. The pots were then watered daily and maintained gravimetrically at $60 \%$ WFPS.

145 Aboveground biomass was harvested at Day 35 by cutting the plants back to approximately $2 \mathrm{~cm}$

146 above the soil surface. The second, third and fourth harvest of biomass were respectively on Day 63,

14791 and 119. Biomass was oven dried at $60^{\circ} \mathrm{C}$ for at least $48 \mathrm{~h}$ and weighed. Subsequently, all biomass

148 from each pot was combined, ground and ball milled. A representative subsample (approx. $2 \mathrm{mg}$ ) of

149 aboveground biomass was then isotopically analysed for ${ }^{13} \mathrm{C}$ and ${ }^{15} \mathrm{~N}$ content as described below.

150 Belowground biomass was collected by washing roots over a $2 \mathrm{~mm}$ sieve to remove soil particles.

151 Roots were then oven-dried and weighed as described above.

\section{Experiment II - Soil gas fluxes}

153 Experiment II consisted of the same three treatments as Experiment I but without plants. Pots 154 (polypropylene $0.5 \mathrm{~L}-6.6 \mathrm{~cm}$ diameter) were packed with $200 \mathrm{~g}$ soil dry weight (dw) to a dry bulk 155 density of $1.2 \mathrm{~g} \mathrm{~cm}^{-3}$. All treatments were replicated 5 times, totalling 15 pots. The pots were placed 156 on a table in a completely randomized design in a climate-controlled room at $20^{\circ} \mathrm{C}$ and maintained 157 at $60 \%$ WFPS.

158 On days $1,2,5,8,16,22,29,36,43,50,57,64$, and $71, \mathrm{CO}_{2}$ and $\mathrm{N}_{2} \mathrm{O}$ gas samples were taken and 159 fluxes were measured. This was done one hour after closing the pot with a lid containing two septa. 
Two separate gas samples $(7 \mathrm{ml}$ each) were taken with a syringe and injected into pre-evacuated $4.5 \mathrm{ml}$ borosilicate vials for analysis of ${ }^{13} \mathrm{C}-\mathrm{CO}_{2}$ and ${ }^{15} \mathrm{~N}-\mathrm{N}_{2} \mathrm{O}$ content. Soil gas fluxes were then quantified following a standard procedure with photoacoustic gas monitor (Brüel \& Kjær, Monitor

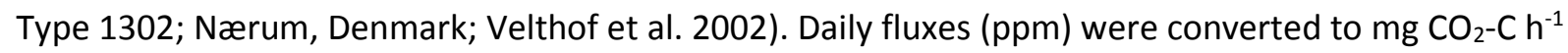
$\mathrm{m}^{-2}$ and $\mu \mathrm{g} \mathrm{N} \mathrm{N}_{2} \mathrm{O}-\mathrm{N} \mathrm{h}^{-1} \mathrm{~m}^{-2}$ and to cumulative fluxes in $\mathrm{g} \mathrm{CO}_{2}-\mathrm{C} \mathrm{m}^{-2}$ and $\mathrm{mg} \mathrm{N}_{2} \mathrm{O}-\mathrm{N} \mathrm{m}^{-2}$ assuming linearity of flux rate between each measurement day.

\section{Stable Isotope analyses}

All isotope analyses were performed at The Stable Isotope Facility of University California, Davis. The

${ }^{13} \mathrm{C}$ content analyses were performed using a ThermoScientific PreCon-GasBench system interfaced to a ThermoScientific Delta V Plus isotope ratio mass spectrometer (ThermoScientific, Bremen, Germany). The ${ }^{15} \mathrm{~N}$ content analyses were performed using a ThermoFinnigan GasBench + PreCon trace gas concentration system interfaced to a ThermoScientific Delta $V$ Plus isotope-ratio mass spectrometer (Bremen, Germany). Percentage $\mathrm{C}$ and $\mathrm{N}$ derived from the biochar and feedstock were calculated using ${ }^{13} \mathrm{C}$ and ${ }^{15} \mathrm{~N}$ gas values and applying the equation of Bedard-Haughn et al. (2003). These percentage values were then used to calculate the $\mathrm{g} \mathrm{CO}_{2}-\mathrm{C} \mathrm{m}^{-2}$ and $\mathrm{mg} \mathrm{N} \mathrm{N}_{2} \mathrm{O}-\mathrm{N} \mathrm{m}^{-2}$, as a proportion of the total flux, derived from the Biochar and Residue.

On Day 71 , the soil from each pot was sieved to pass $4 \mathrm{~mm}$, homogenised by thorough mixing and split into sub-samples for analysis. A representative subsample $(50 \mathrm{mg})$ of the soil was analysed $\left({ }^{13} \mathrm{C}\right.$ and ${ }^{15} \mathrm{~N}$ content) as described below. The $\mathrm{pH}$ and EC was determined after shaking each sample (5 g) for $1 \mathrm{~h}$ with demi-water $(1: 5 \mathrm{w} / \mathrm{v})$.

\section{Microbial biomass ${ }^{15} \mathrm{~N}$}

Determination of microbial biomass $N(M B N)$ was undertaken via an extension of the chloroform fumigation extraction (Vance et al. 1996). In short, soil ( $20 \mathrm{~g}$ ) was shaken for 1 hour with $80 \mathrm{ml} 0.5 \mathrm{M}$ 
$\mathrm{KCl}$ following 24 hours of fumigation. After shaking, extracts were filtered to pass $0.45 \mu \mathrm{m}$. The difference in total soluble $\mathrm{N}$ content (TSN) between the fumigated and non-fumigated soil in the $\mathrm{KCl}$ extract was used to calculate the MBN. Microdiffusion was used to quantify the ${ }^{15} \mathrm{~N}$ content of MBN (Stark and Hart 1996) through the analysis of ${ }^{15} \mathrm{~N}$ that was obtained on the filter. Each glass microfiber filter used for the microdiffusion was put in tin capsules and analysed for ${ }^{15} \mathrm{~N}$ content as described above.

\section{${ }^{13}$ C PLFA}

The phospholipid fatty acid (PLFA) extraction and analysis as outlined by Bligh and Dyer (1959) and extended upon by Zelles (1999) was utilised to determine microbial community level phenotypes. Extractions were performed using 5-g aliquots of soil for each sample. Extracted PLFAs were analysed by gas chromatography using an HP 5 column on a G2070AA Chemstation, Model 6890N, gas chromatography appliance (Agilent Technologies, Santa Clara, California, USA). Peaks were compared with known retention times on the basis of a Supelco 26 peak standard to identify individual PLFAs (Sigma-Aldrich Ltd, Poole, Dorset, UK). The fungal:bacterial ratio was calculated using 18:2w6 (fungal

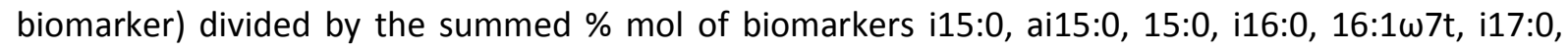

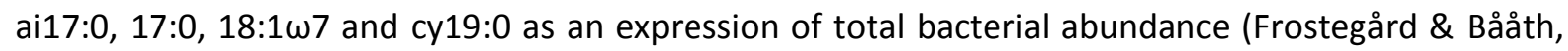
1996). $\delta^{13} \mathrm{C}$ values were measured on a Finnigan Delta-S gas chromatograph-isotope ratio monitoring mass spectrometer (GC-IRMS) as described in Boschker (2004). The increase in $\delta^{13} \mathrm{C}$ values of PLFAs in the treatments compared to the control indicates microbial uptake of labelled $\mathrm{C}$ from the amended material.

\section{Data analysis}

For statistical analyses, SPSS Statistics 19 (IBM) was used with the exception of Principal Component Analysis used to analyse PLFA profiles, which was performed using R Studio (version 0.99 .903 ) with the Vegan package. The effects of the treatments (Biochar, Reside and Control) on cumulative fluxes 
of $\mathrm{CO}_{2}$ and $\mathrm{N}_{2} \mathrm{O}$, the ${ }^{13} \mathrm{C}$ and ${ }^{15} \mathrm{~N}$ content, $\mathrm{pH}$ and $\mathrm{EC}$ of the incubation soil, $\mathrm{N}$ content of the incubation soil and the microbial biomass $\mathrm{N}$ were compared using a one-way Analysis of Variance (ANOVA). Individual comparisons were performed using a Tukey's HSD post hoc test. The effects of the treatments on plant performance and ${ }^{13} \mathrm{C}$ and ${ }^{15} \mathrm{~N}$ uptake by plants were compared using ANCOVA with the number of plants per pot included as a covariate. The treatment effects on daily $\mathrm{CO}_{2}$ and $\mathrm{N}_{2} \mathrm{O}$ fluxes and the ${ }^{13} \mathrm{C}$ and ${ }^{15} \mathrm{~N}$ content were tested with a repeated measures ANOVA.

\section{Results}

\section{Experiment 1: Plant growth}

Despite the germination layer an average of 5.3 (S.E. 1.16), 5.2 (S.E. 1.2) and 8.4 (S.E. 0.68) plants germinated in Biochar, Residue and Control, respectively. Aboveground biomass production of $L$. perenne (dry weight) was significantly reduced by $89 \%$ in the first harvest of Residue compared to Control (Fig. 1). However, biomass production in Residue was significantly higher than Control over the next three harvests. On average, biomass production was approx. $40 \%$ and approx. $60 \%$ higher than Control for Biochar and Residue, $(P=0.001$ and $P=0.01$, resp.). Belowground biomass increased significantly in Biochar by $115 \%$ compared to Control; no significant difference was observed in belowground biomass production in Residue compared to Control. (Fig. 1). Differences in the shoot:root ratio between treatments were close to significant $(P=0.064)$.

Significant differences in $\mathrm{N}$ uptake were observed between Biochar and Residue $(\mathrm{P}<0.001)$. Overall, more $\mathrm{N}$ was taken up by plants from the amended material in Reside than in Biochar (Fig. 2 a \& b). At first harvest, significantly more $\mathrm{N}$ was taken up from the amended material in Biochar than in Residue in absolute terms $(\mathrm{P}<0.001$; Figure $2 \mathrm{a})$. However, as a proportion of total $\mathrm{N}$ taken up over all harvests, significantly more plant $\mathrm{N}$ was derived from the amended material in Residue than in Biochar ( $\mathrm{P}<0.001 ;$ Fig. 2 b). After the first harvest, approximately 2 to $2.5 \%$ of $\mathrm{N}$ taken up by plants in 
Residue was derived from the amended material. For Biochar, this was less than $0.5 \%$ for all harvests (Figure $2 \mathrm{~b}$ ). After four harvests, biochar $\mathrm{N}$ accounted for approx. $0.4 \%$ of total plant $\mathrm{N}$ whereas for residue $\mathrm{N}$ this was approx. $2 \%$.

\section{Experiment 2: Soil gas fluxes}

Cumulative $\mathrm{N}_{2} \mathrm{O}$ fluxes from Biochar did not vary significantly from Control throughout the timeframe of the experiment $\left(P=0.9\right.$; Fig. 3a). Residue resulted in a significantly greater release of $\mathrm{N}_{2} \mathrm{O}$ than either Control or Biochar up to Day $5\left(\mathrm{P}<0.001\right.$; Figure 3a). The $\mathrm{N}_{2} \mathrm{O}$ flux from Reside was reduced greatly after this initial flush but increased again at Day 64 until the end of the experiment.

After 71 days, at the end of the incubation experiment, approximately $0.3 \%$ of amended $\mathrm{N}$ had been lost as $\mathrm{N}_{2} \mathrm{O}$ from the amendment in Residue, compared to $0.05 \%$ from Biochar (Fig. 3). N-loss from the amended material in Biochar as $\mathrm{N}_{2} \mathrm{O}$ was significantly lower than from Residue $(P<0.01)$ suggesting decreased availability of $\mathrm{N}$ from biochar than residue. However, $\mathrm{N}_{2} \mathrm{O}$ did not represent a significant source of $\mathrm{N}$ loss from either experimental treatment.

\% \%By Day 2, significantly higher cumulative $\mathrm{CO}_{2}$ fluxes were measured in Residue compared to Biochar and Control $(P=0.001)$; this difference increased throughout the incubation period. There was no significant difference in total cumulative fluxes between Biochar and Control $(P=0.96$; Fig. 3b). Significantly more $C$ was lost from Residue by Day 5 (Fig 3d; $P=0.008$ ); by the end of the experiment approx. $20 \%$ of the applied $\mathrm{C}$ was lost from Residue as $\mathrm{CO}_{2}$ compared to approx. $2 \%$ loss from Biochar (Fig. 3d). However, the rate of $\mathrm{C}$ loss from biochar reduced greatly after the initial flush.

By the end of the experiment, microbial biomass nitrogen (MBN) was four times higher in Residue than in Biochar or Control ( $\mathrm{P}<0.001$; Fig. 4a). There was no significant difference in MBN between Biochar and Control ( $P=0.78$; Fig. 4a). Stable isotope analysis showed that for the Residue treatment 
approximately $25 \%$ of total MBN was derived from the amended material, while this was only approximately $0.3 \%$ for the Biochar treatment (Fig. 4a).

The $\mathrm{CO}_{2}-\mathrm{C}$ derived from SOM did not differ significantly from Control in either treatment $(\mathrm{P}>0.05$;

Fig. 4b). However, significantly more $\mathrm{CO}_{2}-\mathrm{C}$ was derived from the amended material in Residue than Biochar (56 \% compared to $39 \%$; $\mathrm{P}<0.001$; Fig. 4b). Further, significantly more $\mathrm{C}$ was mineralised from SOM in Residue than Biochar (Fig. 4b; $\mathrm{P}=0.03$ ) showing that both $\mathrm{C}$ pools had increased turnover in Residue.

PLFA profile analysis of the community level microbial phenotype showed strong discrimination between Residue compared to Biochar and Control where little discrimination was evident (Fig. 5a). Discrimination between treatments occurred mainly in PC1, which accounted for $86 \%$ of variation. The PLFAs most responsible for the observed discrimination between treatments were $\mathrm{C} 16: 0$ (general biomarker for microbial biomass), $\mathrm{C} 18: 2 \omega 6 \mathrm{c}$ and $\mathrm{C} 18: 1 \omega 9 \mathrm{c} / 2 \omega 6 \mathrm{t} / 3 \omega$ (saprotrophic fungal biomarkers - note that with the methodology used it was not possible to discriminate between these PLFAs; Fig 5b). The bacterial: fungal ratios were significantly lower in Control (0.03) and Biochar (0.04) compared to Residue $(0.3)(P<0.01)$.

The stable isotope enrichment increased significantly from $-30.4 \%$, $-32.1 \%$ and $-29.4 \%$ in Control to 8.3\%, $5.5 \%$ and $-0.5 \%$ in Biochar and $140 \%, 87.8 \%$ and $154.4 \%$ in Residue for the PLFAs C16:0, C18:2 $\omega 6 c$ and $C 18: 1 \omega 9 c / 2 \omega 6 t / 3 \omega$ respectively (Figure $5 c ; P<0.01$ ).

\section{Discussion}

The increased plant productivity following soil biochar amendment that we found in this study is in agreement with previous studies (Jeffery et al.2011; Spokas et al. 2012; Liu et al. 2013). However, the use of stable isotope probing allows us to investigate the mechanisms underlying this effect, rather than reporting results at the systems level. Previous biochar studies using soil from the same site 
showed that micronutrients in the soil used were not limiting (Oram et al. 2014; van de Voorde et al. 2014). In the present study, soils were fertilized with $K$ and $P$ to ensure that only $N$ would be limiting (Table 2). Total plant production in Biochar and Residue was significantly higher than Control. Concurrently, stable isotope analysis demonstrated uptake of $\mathrm{N}$ from both Residue and Biochar. Therefore, the data support the hypothesis that observed differences in biomass production resulted from an $\mathrm{N}$ fertilisation from the amendment in the Biochar and Residue treatments. Plant $\mathrm{N}$ uptake from the amended material Residue was 7.6 times higher than in Biochar. Differences in biomass production were less apparent. Once $\mathrm{N}$ limitation has been alleviated, diminishing returns are expected from further increased $\mathrm{N}$ availability (Tillman et al. 2002). This effect was reflected in the biomass data.

Increased root growth was noted in Biochar compared to Residue and Control (Fig. 1). It has previously been reported that plants grown in biochar-amended soils can have increased "rhizosphere zones" compared to controls (Prendergast-Miller et al. 2014). During harvest, we noted that the rhizosphere contained more biochar particles than the bulk soil suggesting that roots may prefer soil containing biochar particles. This may have consequences beyond investigated effects in this experiment. For example, increased rooting may help alleviate the impact of drought as well as aiding nutrient acquisition beyond those included in the amended material. The trigger that led to increased root growth in the presence of biochar remains unclear and a necessary area for further research.

The same amendment application rate was used for Biochar and Residue. As they each contained very similar levels of $\mathrm{N}$ (Table 2), similar rates of $\mathrm{N}$ were applied to both treatments. However, the $\mathrm{C}: \mathrm{N}$ of the applied materials differed significantly. It is not yet clear how the C:N stoichiometery interacts with soil processes as it is likely the quality of the $C$ that is important rather than the quantity. In the Residue treatment more than four times as much $\mathrm{N}$ was taken up from the amendment than in the Biochar treatment showing enhanced ANR from the amended material in 
Residue than Biochar. However, initial $\mathrm{N}$ immobilisation reduced ANR significantly at the first harvest in Residue. Such immobilisation was not observed in Biochar where ANR was shown to be highest at first harvest (Fig 2a and b) where it then decreased and remained at a consistent level thereafter. Biochar could have been expected to stimulate $\mathrm{N}$ immobilisation more than residue when considering only the $\mathrm{C}: \mathrm{N}$ ratios alone. That this did not occur provides evidence that the $\mathrm{C}: \mathrm{N}$ ratio of biochar is likely not an effective predictor as to whether that biochar will immobilise $\mathrm{N}$ when applied to soil.

There are few data on the availability of $\mathrm{N}$ from biochar (Clough et al. 2013; Cayuela et al. 2014). Studies that have investigated $\mathrm{N}$ dynamics following biochar application have typically focused on coapplication of $\mathrm{N}$ fertilizer (Spokas et al. 2012; Zheng et al. 2012; Clough et al. 2013), N retention effects of biochar (Spokas et al. 2012; Zheng et al. 2012), or $\mathrm{N}_{2} \mathrm{O}$ flux effects (Zheng et al. 2012; Clough et al. 2013). However, no other study to date has quantitatively analysed the bioavailability of $\mathrm{N}$ from biochar itself. Our study shows that pyrolysis reduced availability of $\mathrm{N}$ for plant uptake in Biochar by $>700 \%$ compared to Residue, but that a significant proportion of $\mathrm{N}$ remained bioavailable (or mineralisable to available forms). Reduced $\mathrm{N}$ bioavailability led to decreased plant productivity in Biochar compared to Residue, while still being greater than Control. Plant biomass productivity was lowest in Control due to $\mathrm{N}$ limitation as it received no amendment (i.e. no input of $\mathrm{N}$ ).

The significant decrease in plant biomass in Residue compared to Biochar and Control at the first harvest suggests $\mathrm{N}$ immobilisation. This was likely a consequence of the addition of the relatively large amounts of labile $\mathrm{C}$ added to this treatment (i.e. plant residue) as reflected in the $\mathrm{CO}_{2}$ emission rate (Fig. 3). This is also reflected in the fact that very little $\mathrm{N}$ was taken up by plants from the amendment in Residue by the first harvest, and that microbial biomass $\mathrm{N}$ was significantly larger in the Residue treatment. Isotopic analysis showed that $0.3 \%$ of MBN was derived from the amendment Biochar, compared to $22.5 \%$ in Residue. This agrees with previous work that found little effect of biochar on MBN in contrast to wheat straw (Zhang et al. 2014). This was likely due to the 
application of labile C (i.e. plant material) provided substrate that functioned as an energy source allowing microbes to scavenge for $\mathrm{N}$ from SOM through nitrogen-mining (Craine et al. 2007).

There was a significant increase in $\mathrm{N}_{2} \mathrm{O}$ production from Residue for the first 5 days of the incubation experiment indicative of increased microbial $\mathrm{N}$ cycling in this period. After this time, $\mathrm{N}_{2} \mathrm{O}$ fluxes decreased greatly suggesting that readily available $N$ in the soilwas immobilised in the microbial community, or denitrification increased due to depletion of $\mathrm{O}_{2}$ within soil pores driven by respiration of labile $\mathrm{C}$ as. By the end of the incubation there was no significant difference in cumulative $\mathrm{N}_{2} \mathrm{O}$ emissions between treatments. This result contrasts with numerous studies which have reported a significant decrease (Cayuela et al. 2014; Case et al. 2015), or increase (Clough et al. 2010; SánchezGarcía et al. 2014) in $\mathrm{N}_{2} \mathrm{O}$ fluxes following biochar application to soil. However, other studies have also reported no effect on $\mathrm{N}_{2} \mathrm{O}$ emissions (Suddick et al. 2013), or different effects from the same biochar applied to different soils (Yoo et al. 2012). These contrasting findings emphasise that generalisation of the effects of biochar should be taken with great care and that the results may depend greatly on characteristics of the biochar and soil used. It should be noted that we used a coarse soil (Table 2) and as such our results may differ from experiments that used a fine soils.

Utilisation of ${ }^{13} \mathrm{C}$ isotopes allowed proportional attribution of $\mathrm{CO}_{2}$ flux to the different carbon pools in biochar and SOM (Boschker et al. 1998). ${ }^{13} \mathrm{C}$ analysis confirmed that a portion of emitted $\mathrm{CO}_{2}$ was derived from biochar and that the biochar therefore contained a labile component. However, data presented here demonstrate that the $\mathrm{C}$ in the biochar was, on the whole, significantly more recalcitrant than the unpyrolysed feedstock with $>3 \%$ of amended C lost from Biochar over the course of the experiment compared to $19 \%$ of amended C lost from Residue. We found no evidence of priming of SOM by addition of Biochar and Residue compared to the control. However, mineralisation rates of SOM differed between the Biochar and Residue treatments. This means that while no priming of SOM occurred compared to the control situation with no addition, differential interactions with SOM in terms of priming effects were observed following the application of Biochar 
versus Residue. This was likely due to the increased microbial biomass (as suggested by the increased MBN in Residue; Fig. 4a) which is generally correlated with increased decomposition of soil organic matter (Balota et al. 2003; Lee et al. 2003). The decay constant (k) of SOM are usually imperfect representations of first order kinetics (Paul et al. 1996). As such linear extrapolation cannot be undertaken with confidence but the evidence suggests the residence time of the biochar $\mathrm{C}$ would be at least an order of magnitude greater than that of residue $C$.

Biochar application to soil has been shown to stimulate mycorrhizal fungi and their colonisation of plant roots (Warnock et al. 2007). We quantified microbial community effects through phenotypic fingerprinting using ${ }^{13} \mathrm{C}$ PLFA. While PLFA discriminated between the microbial community in Residue compared to Biochar and Control, no strong discrimination between biochar and control was observed. The PLFA 16:1w5 considered a biomarker for mycorrhizal fungi (Olsson 1995) did not vary significantly between treatments suggesting that, at least in our study, observed yield effects should not be attributed to increased mycorrhizal fungi as has been posited previously (Warnock et al. 2007). However, the plant used in this experiment, Lolium perenne, forms a dense rooting system that may not be conducive to mycorrhizal colonisation. Further, the soil is relatively high in P (Table 2), and was fertilised with soluble $P$, which tends to reduce mycorrhization. As such, different results may have been observed if different plants or different fertilisation regimes were used. The PLFA C16:0, considered a general microbial biomass marker (Bossio et al. 1998) and C18:1 $\omega 9 \mathrm{c} / 2 \omega 6 \mathrm{t} / 3 \omega$

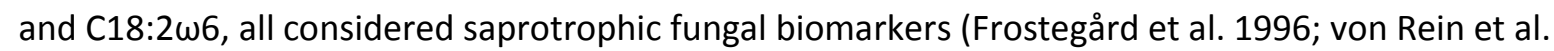
2016), contributed most to the discrimination observed between treatments. The $\delta^{13} C$ of these PLFAs all increased significantly from Control to Biochar to Residue. This further confirms that some of the $\mathrm{C}$ in the biochar was labile and so available for microbial utilisation and incorporation into microbial cell membranes. However, considerably more $\mathrm{C}$ was incorporated into microbial cell membranes (and likely microbial cells in general) in Residue, as confirmed by the greatly increased $\delta^{13} \mathrm{C}$. These data are again consistent with the fertilisation hypothesis. This evidence suggests that saprotrophic 
375 fungal biomass increased in Biochar, and much more so in Residue, where it decomposed the

376 amended material and mineralised organic $\mathrm{N}$ into plant available forms.

\section{Conclusions}

378 Our results demonstrate that the observed increases in plant productivity following biochar addition

379 to soil were due to an $\mathrm{N}$ fertilisation effect. Stable isotope analysis using ${ }^{13} \mathrm{C}$ confirmed that the $\mathrm{C}$ in

380 biochar is considerably more recalcitrant than the feedstock from which it was produced.

Pyrolysis strongly reduced the bioavailability of $\mathrm{N}$ from the resulting biochar when compared to the initial feedstock. This means that nutrients in biochar are released slowly when compared to the initial feedstock. Further, due to the increased recalcitrance of the $\mathrm{C}$ in biochar, application of biochar to soil did not cause $\mathrm{N}$ immobilisation. Therefore, application of biochar rather than crop residues may circumvent the need of co-application of synthetic $\mathrm{N}$ fertilisers, which are sometimes applied to compensate for the effects of microbial $\mathrm{N}$ immobilisation. This study also highlights the need for rigorous controls in experiments to allow distinguishing fertilisation effects (short-term) from the "true" biochar effects, i.e. those effects associated with biochar $C$ that will occur over the entire residence time of that $\mathrm{C}$ in the soil. For sustainable application of biochar it is vital to make informed decisions on where best to apply biochar, compost and/or green manures to maximise the

391 potential benefits and minimise the negative impacts. Our results will help decisions makers such as 392 farmers or policy makers to do so. 


\section{Acknowledgements}

394 We gratefully acknowledge funding support from the Marie Curie Career Integration Grant (No.

395 GA526/09/1762) and funding from the Emerging Science fund of the Production Ecology and

396 Resource Conservation (PE\&RC) graduate school of Wageningen UR, Netherlands. We are also

397 grateful for the assistance of André Maassen for watering plants, and Jaap Nelemans and Willeke van

398 Tintelen for technical assistance in the laboratory and Ana Prada for assistance with formatting.

399 
401

402

403

404

405

406

407

408

409

410

411

412

413

414

415

416

417

418

419

420

421

Balota E, Colozzi-Filho A, Andrade D and Dick R 2003 Microbial biomass in soils under different tillage and crop rotation systems. Biology and Fertility of Soils 38, 15-20 DOI 10.1007/s00374-003-0590-9

Bedard-Haughn A, van Groenigen J W and van Kessel C 2003 Tracing ${ }^{15} \mathrm{~N}$ through landscapes: potential uses and precautions. Journal of Hydrology 272, 175-190 DOI 10.1016/S00221694(02)00263-9

Boschker J T, Nold S C, Wellsbury P, Bos D, de Graaf W, Pel R, Parkes R J and Cappenberg T E 1998 Direct linking of microbial populations to specific biogeochemical processes by ${ }^{13} \mathrm{C}$-labelling of biomarkers. Nature 392, 801-805 DOI:10.1038/33900

Bossio D A and Scow K M 1998 Impacts of carbon and flooding on soil microbial communities: Phospholipid fatty acid profiles and substrate utilization patterns. Microbial Ecology 35, 265-278 DOI:10.1007/s002489900082

Bromand S, Whalen J, Janzen H H, Schjoerring J and Ellert B H 2001 A pulse-labelling method to generate ${ }^{13} \mathrm{C}$ - enriched plant materials. Plant and Soil 235, 253-257 DOI:

10.1023/A:1011922103323

Case S D C, McNamara N P, Reay D S, Stott A W, Grant H K and Whitaker J 2015 Biochar suppresses $\mathrm{N}_{2} \mathrm{O}$ emissions while maintaining $\mathrm{N}$ availability in a sandy loam soil. Soil Biology and Biochemistry 81, 178-185 DOI: 10.1016/j.soilbio.2014.11.012

Cayuela M L, Sánchez-Monedero M A, Roig A, Hanley K, Enders A and Lehmann J 2013 Biochar and denitrification in soils: when, how much and why does biochar reduce $\mathrm{N}_{2} \mathrm{O}$ emissions? Scientific Reports 3, 1732 doi:10.1038/srep01732

Cayuela M L, van Zwieten L, Singh B P, Jeffery S, Roig A and Sánchez-Monedero M A 2014 Biochar's 
422

role in mitigating soil nitrous oxide emissions: A review and meta-analysis. Agriculture, Ecosystems and Environment 191, 5-16 doi: 10.1016/i.agee.2013.10.009

Clough T J, Bertrama J E, Raya J L, Condron L M, O'Callaghan M, Sherlock R R and Wells N S 2010

Unweathered Wood biochar impact on nitrous oxide emissions from a bovine-urine-amended pasture soil. Soil Science Society of America Journal 74, 852-860 doi:10.2136/sssaj2009.0185

Clough T, Condron L, Kammann C and Müller C 2013 A review of biochar and soil nitrogen dynamics. Agronomy 3, 275-293 doi:10.3390/agronomy3020275

Cornelissen G, Gustafsson O, Bucheli T D, Jonker M T O, Koelmans A A and van Noort P C M 2005 Extensive sorption of organic compounds to black carbon, coal, and kerogen in sediments and soils: Mechanisms and consequences for distribution, bioaccumulation, and biodegradation. Environmental Science and Technology 39, 6881-6895 DOI: 10.1021/es050191b

Craine J M, Morrow C and Fierer N 2007 Microbial nitrogen limitation increases decomposition. Ecology 88, 2105-13 DOI: 10.1890/06-1847.1

Crombie K, Mašek O, Cross A and Sohi S 2015 Biochar - synergies and trade-offs between soil enhancing properties and C sequestration potential. GCB Bioenergy 7, 1161-1175 DOI: 10.1111/gcbb.12213

Fang Y, Singh B, Singh B P and Krull E 2014 Biochar carbon stability in four contrasting soils. Eur J Soil Sci 65, 60-71 DOI: 10.1111/ejss.12094

Frostegård A and Bååth E 1996 The use of phospholipid fatty acid analysis to estimate bacterial and fungal biomass in soil. Biology and Fertility of Soils 22, 59-65 DOI: 10.1007/BF00384433

Gurwick N P, Moore L A, Kelly C and Elias P 2013 A systematic review of biochar research, with a focus on its stability in situ and its promise as a climate mitigation strategy. PLoS ONE 8, e75932 doi: 
445 Hodgson E. M. et al. 2011 Variation in Miscanthus chemical composition and implications for 446 conversion by pyrolysis and thermo-chemical bio-refining for fuels and chemicals. Bioresource

447 Technology 102, 3411-3418 DOI: 10.1016/j.biortech.2010.10.017

448 Janzen H H 2006 The soil carbon dilemma: Shall we hoard it or use it? Soil Biology and Biochemistry $449 \quad 38,419-424$

450 Jeffery S, Abalos D, Spokas K and Verheijen, F G A 2015a Biochar effects on crop yields. In Biochar for 451 Environmental Management: Science, Technology and Implementation. Eds J Lehmann and S Joseph. pp. 301-326 Earthscan, London Jeffery S, Bezemer T M, Cornelissen G, Kuyper T W, Lehmann J, Mommer L, Sohi S P, van de Voorde T 454 F J, Wardle D A and van Groenigen J W 2015b The way forward in biochar research: targeting trade455 offs between the potential wins. GCB Bioenergy 7, 1-13 Jeffery S, Verheijen F G A, van der Velde M and Bastos A C 2011 A quantitative review of the effects of biochar application to soils on crop productivity using meta-analysis. Agriculture, Ecosystems and Environment 144, 175-187

Karaosmanoğlu F, Işıḡıgür-Ergüdenler A and Sever A 2000 Biochar from the straw-stalk of rapeseed plant. Energy and Fuels 14, 336-339

Kuchenbuch R, Claassen N and Jungk A 1986 Potassium availability in relation to soil moisture. Plant and Soil 95, 221-231 
Lee K-H and Jose S 2003 Soil respiration, fine root production, and microbial biomass in cottonwood and loblolly pine plantations along a nitrogen fertilization gradient. Forest Ecology and Management $185,263-273$

Lehmann J, Gaunt J and Rondon M 2006 Bio-char sequestration in terrestrial ecosystems - A Review. $11,395-419$

Lehmann J, Pereira da Silva Jr J, Steiner C, Nehls T, Zech W and Glaser B 2003 Nutrient availability and leaching in an archaeological Anthrosol and a Ferralsol of the Central Amazon basin: fertilizer, manure and charcoal amendments. Plant and Soil 249, 343-357

Liu X, Zhang A, Ji C, Joseph S, Bian R, Li L, Pan G and Paz-Ferreiro J 2013 Biochar's effect on crop productivity and the dependence on experimental conditions-a meta-analysis of literature data. Plant and Soil 373, 583-594

Maestrini B, Nannipieri P and Abiven S 2014 A meta-analysis on pyrogenic organic matter induced priming effect. GCB Bioenergy 7, 577-590

Mia S, van Groenigen J W, van de Voorde T F J, Oram N J, Bezemer T M, Mommer L, and Jeffery S 2014 Biochar application rate affects biological nitrogen fixation in red clover conditional on potassium availability. Agriculture, Ecosystems and Environment 191, 83-91

Mukherjee A and Lal R 2014 The biochar dilemma. Soil Research 52, 217-230

Nelissen V, Rütting T, Huygens D, Ruysschaert G and Boeckx P 2015 Temporal evolution of biochar's impact on soil nitrogen processes $-\mathrm{a}{ }^{15} \mathrm{~N}$ tracing study. GCB Bioenergy 7, 635-645

Olsson P A, Bååth E, Jakobsen I and Söderström B 1995 The use of phospholipid and neutral lipid fatty acids to estimate biomass of arbuscular mycorrhizal fungi in soil. Mycological Research 99, 623629 
Oram N J, van de Voorde T F J, Ouwehand G A, Bezemer T M, Mommer L, Jeffery S and Van Groenigen J W 2014 Soil amendment with biochar increases the competitive ability of legumes via increased potassium availability. Agriculture, Ecosystems and Environment 191, 92-98

Paul E A, Paustian K H, Elliott E T and Cole C V 1996 Soil Organic Matter in Temperate Agroecosystems - Long Term Experiments in North America. CRC Press, Taylor Francis Group, USA

Prendergast-Miller M T, Duvall M and Sohi S P 2014 Biochar-root interactions are mediated by biochar nutrient content and impacts on soil nutrient availability. Eur J Soil Sci 65, 173-185

Sagrilo E, Jeffery S, Hoffland E and Kuyper T W 2015 Emission of $\mathrm{CO}_{2}$ from biochar-amended soils and implications for soil organic carbon. GCB Bioenergy 7, 1294-1304

Sánchez-García M, Roig A, Sanchez-Monedero M A and Cayuela M L 2014 Biochar increases soil $\mathrm{N}_{2} \mathrm{O}$ emissions produced by nitrification-mediated pathways. Frontiers in Environmental Science 2

Singla A, Iwasa H and Inubushi K 2014 Effect of biogas digested slurry based-biochar and digested liquid on $\mathrm{N}_{2} \mathrm{O}, \mathrm{CO}_{2}$ flux and crop yield for three continuous cropping cycles of komatsuna (Brassica rapa var. perviridis) Biological Fertility of Soils 50, 1201-1209

Shackley S, Sohi S P, Ibarrola R, Hammond J, Mašek O, Brownsort P, Cross A, Prendergast-Miller M and Haszeldine S 2012 Biochar, Tool for Climate Change Mitigation and Soil Management. In Geoengineering Responses to Climate Change. Eds T Lenton and N Vaughan. pp. 73-140 Springer, New York

Spokas K A, Cantrell K B, Novak J M, Archer D W, Ippolito J A, Collins H P, Boateng A A, Lima I M, Lamb M C, McAloon A J, Lentz R D and Nichols K A 2012 Biochar: A synthesis of its agronomic impact beyond carbon sequestration. J. Environ. Qual. 41, 973-989 
Stark J M and Hart S C (1996) Diffusion technique for preparing salt solutions, Kjeldahl digests, and persulfate digests for nitrogen-15 analysis. Soil Science Society of America Journal 60, 1846-1855

Stiboka 1975 Stiboka Bodemkaart van Nederland Stiboka, Wageningen, The Netherlands

Suddick E C and Six J 2013 An estimation of annual nitrous oxide emissions and soil quality following the amendment of high temperature walnut shell biochar and compost to a small scale vegetable crop rotation. Science of The Total Environment 465, 298-307

Vance E. Brookes P and Jenkinson D 1987 An extraction method for measuring soil microbial biomass C. Soil Biology and Biochemistry 19, 703-707

Van de Voorde T F J, Bezemer T M, Van Groenigen J W, Jeffery S and Mommer L 2014 Soil biochar amendment in a nature restoration area: effects on plant productivity and community composition. Ecological Applications 24, 1167-1177

von Rein I, Gessler A, Premke K, Keitel C, Ulrich A and Kayler Z E 2016 Forest understory plant and soil microbial response to an experimentally induced drought and heat-pulse event: the importance of maintaining the continuum. Global Change Biology 22, 2861-2874

Velthof G L, Kuikman P J and Oenema O 2002 Nitrous oxide emissions from soils amended with crop residues. Nutrient Cycling in Agroecosystems 62, 249-261

Verheijen F G A, Jeffery S, Bastos A C, van der Velde M and Diafas I 2010 Biochar application to soils A critical scientific review of effects on soil properties, processes and functions. Report No. EUR 24099 EN, Luxembourg

Warnock D, Lehmann J, Kuyper T and Rillig M 2007 Mycorrhizal responses to biochar in soil concepts and mechanisms. Plant and Soil 300, 9-20 
529 Woolf D, Amonette J E, Street-Perrott F A, Lehmann J and Joseph S 2010 Sustainable biochar to

530 mitigate global climate change. Nature Communications 1, 56

531 Yoo G and Kang H 2012 Effects of biochar addition on greenhouse gas emissions and microbial

532 responses in a short-term laboratory experiment. J. Environ. Qual. 41, 1193-1202

533 Zhang Qz, Dijkstra F A, Liu Xr, Wang Yd, Huang J and Ning Lu 2014 Effects of biochar on soil microbial

534 biomass after four years of consecutive application in the North China Plain. PLoS ONE 9, e102062

535 Zheng J, Stewart C E and Cortufo M F 2012 Biochar and nitrogen fertilizer alters soil nitrogen

536 dynamics and greenhouse gas fluxes from two temperate soils. J. Environ. Qual. 41, 1361-1370 


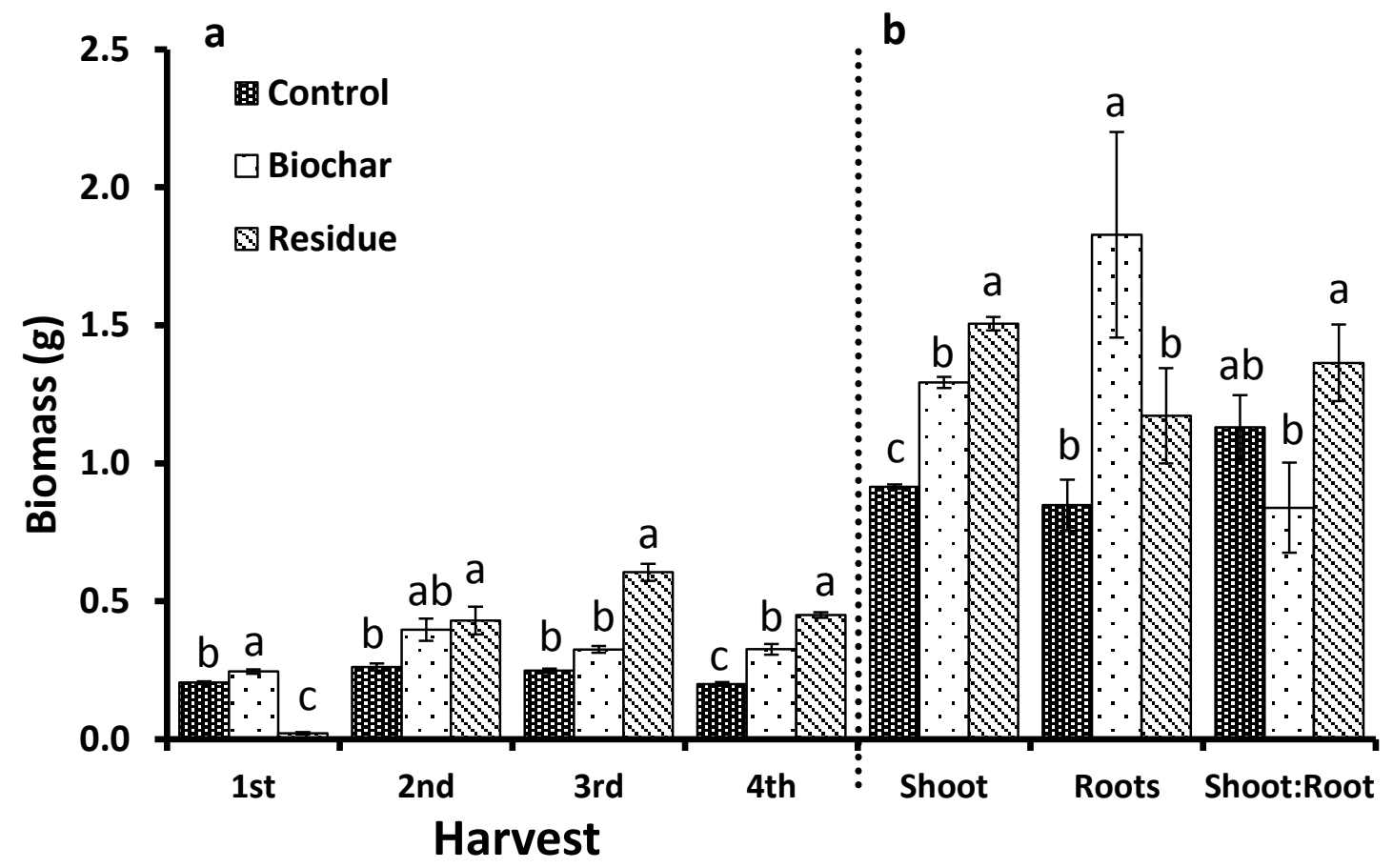




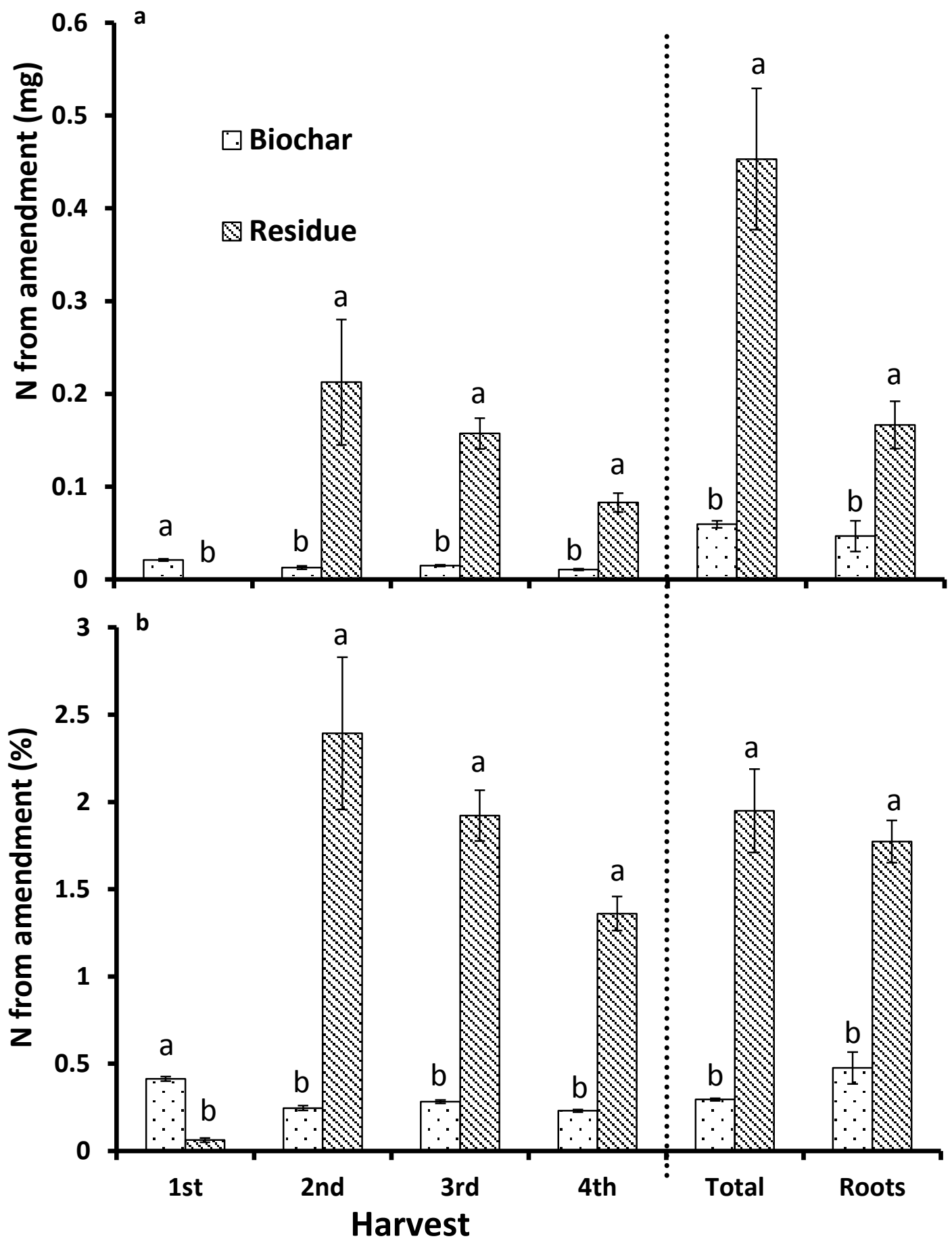



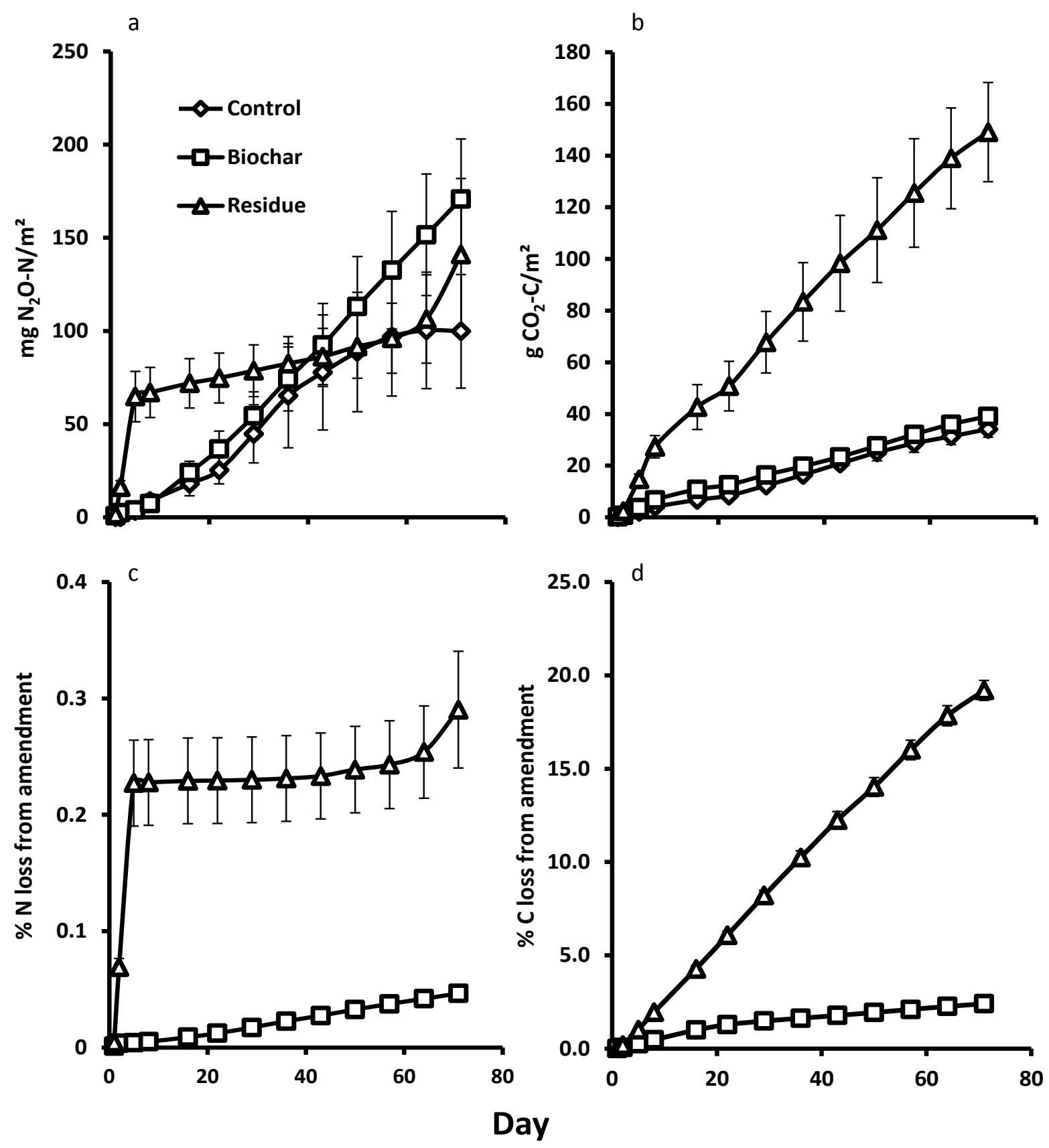

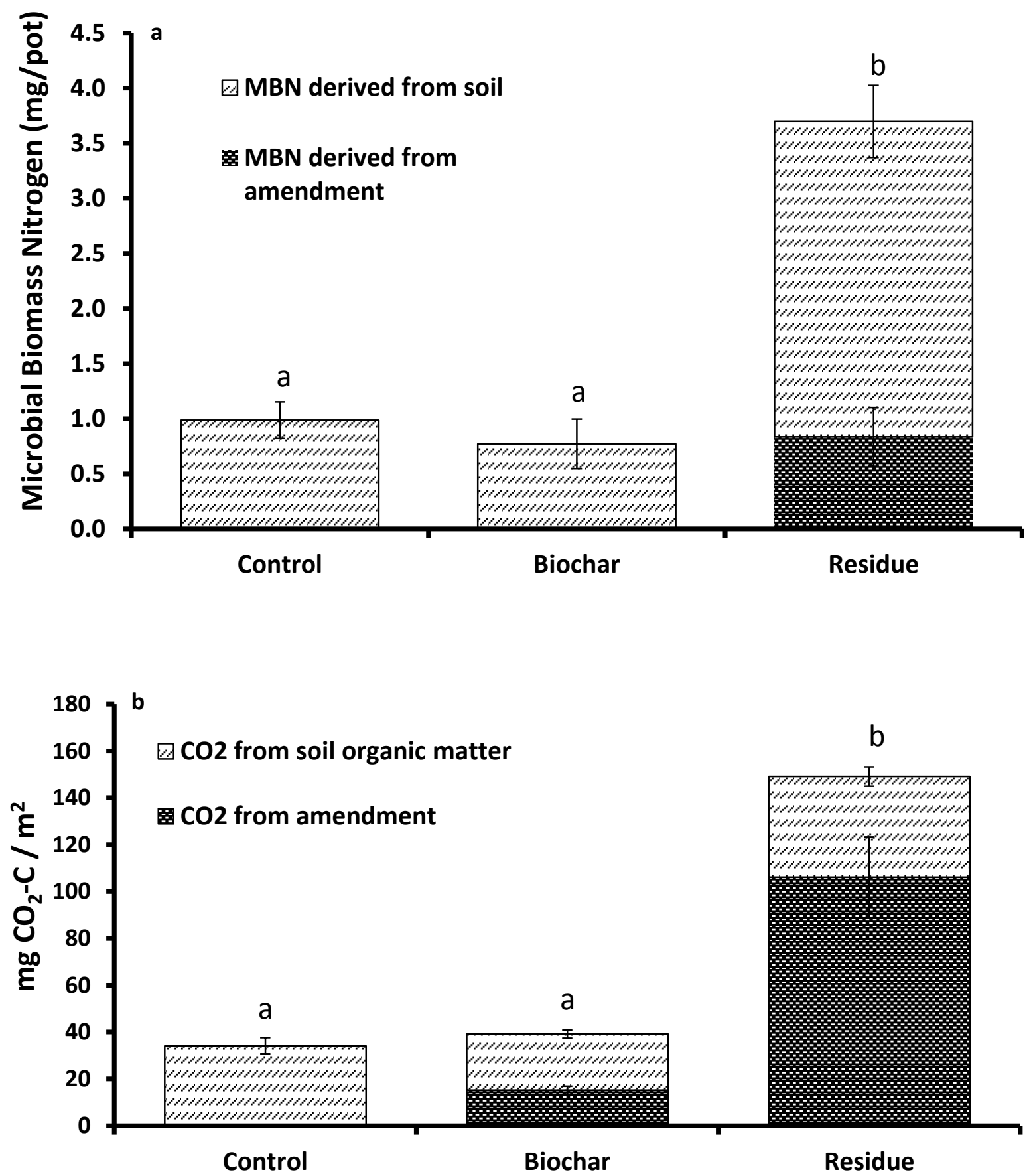

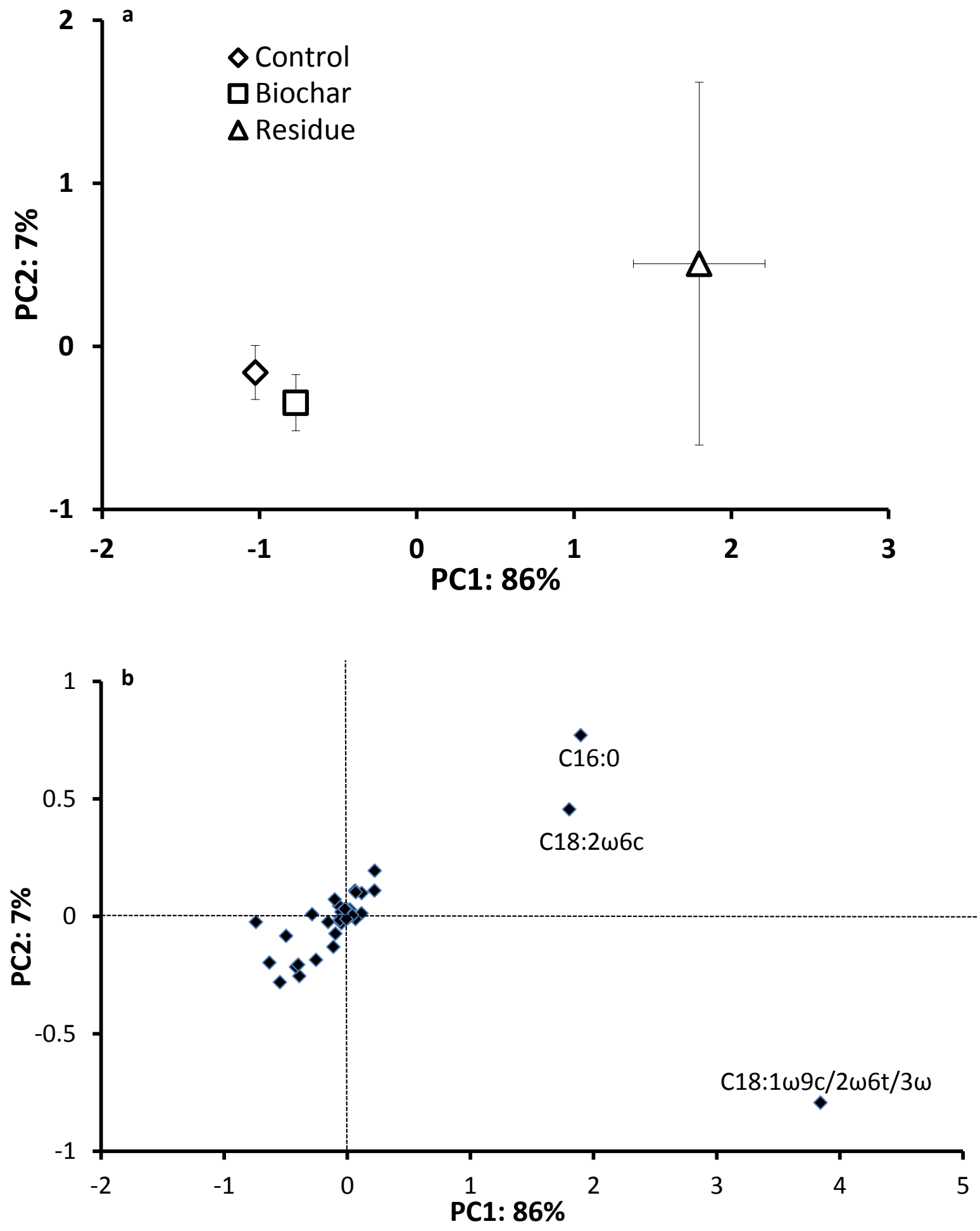


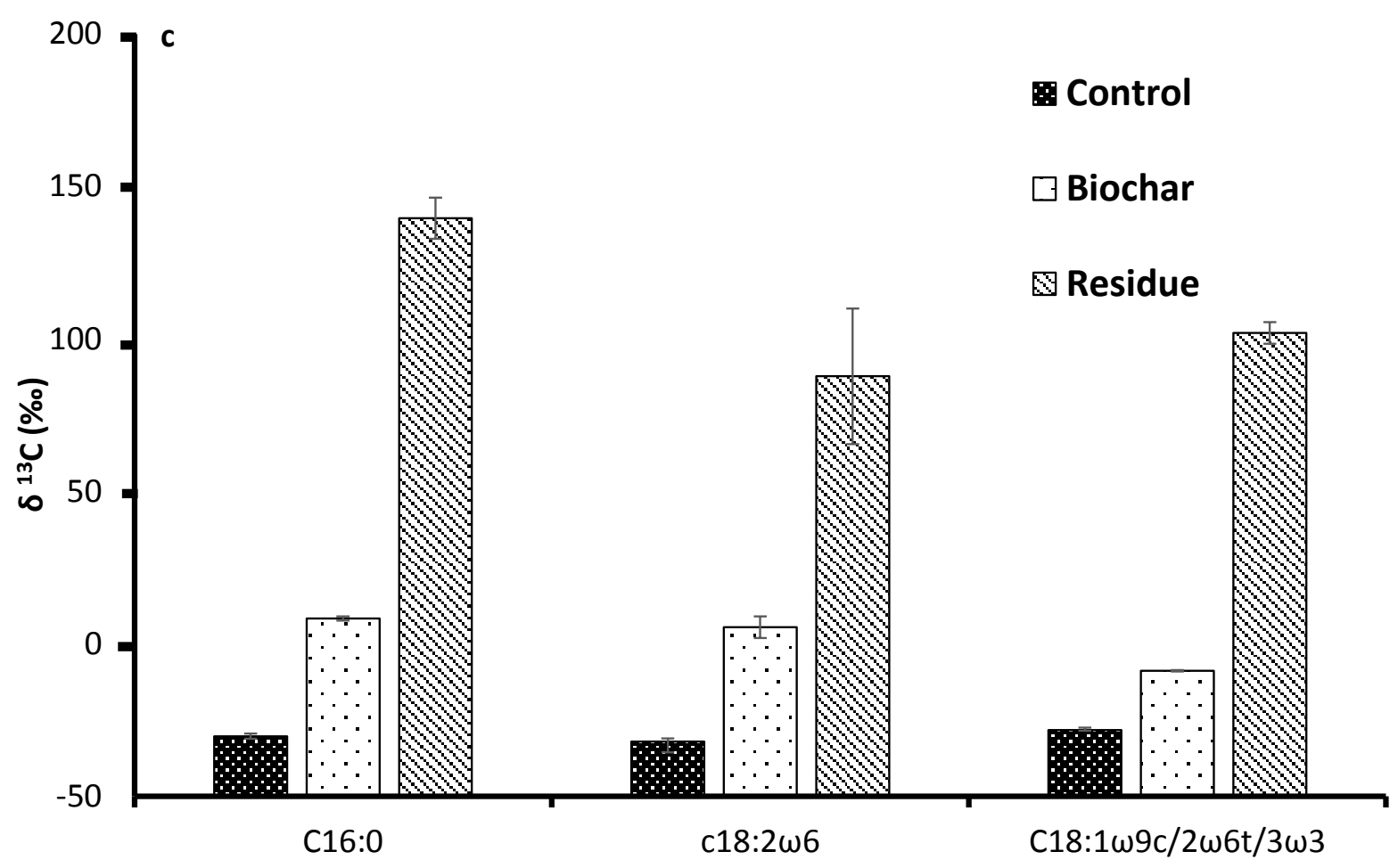


Figure 1a. Lolium perenne biomass (dry weight) produced from each treatment at each of the four harvests after 35, 63, 91 and 119 days; b. total aboveground biomass "Shoot" (i.e. from all harvests combined) and belowground biomass "Roots" (calculated as the average of the belowground biomas produced in each treatment), and the Shoot to Root Ratio after 119 days. Letters show significant differences within each harvest and for plant growth response characteristics. Columns show means, bars show \pm standard error $(n=5)$.

Figure 2. (a) Total amount of $\mathrm{N}$ taken up from the amended material and (b) proportion of plant $\mathrm{N}$ derived from the amended material. Columns show means. Bars show \pm standard errors $(n=5)$. N uptake from amendment was significant different between treatments in all cases $(P=0.05)$. Note that no material was amended to Control and so no data are reported for Control.

Figure 3. Cumulative $\mathrm{N}_{2} \mathrm{O}\left(\mathrm{a}\right.$ ) and $\mathrm{CO}_{2}$ (b) fluxes from microcosms in Exp. Il over a 71 day incubation period and the percent loss of $\mathrm{N}(\mathrm{c})$ and $\mathrm{C}$ (d) from the amended material as determined by ${ }^{15} \mathrm{~N}$ or ${ }^{13} \mathrm{C}$ analysis. Points show means. Bars show \pm standard errors ( $n=5$, apart from Day 2 points where $\mathrm{n}=4$ ). Note that no material was amended to Control and so no data are reported for Control in (c) or (d).

Figure 4. (a) Microbial biomass $N(M B N)$ as determined by chloroform fumigation extraction with the contribution of each pool of $\mathrm{N}$ to microbial biomass $\mathrm{N}$ determined by stable isotope ${ }^{15} \mathrm{~N} 71$ days after application of amended material; (b) Cumulative $\mathrm{CO}_{2}$ emitted from each treatment, derived from each soil C pool using ${ }^{13} \mathrm{C}$ isotope analysis over a 71 day incubation. Columns show means. Shaded columns show the mean contribution of each pool to the total. Bars show \pm standard errors $(n=5)$.

Figure 5 (a) A principal component ordination plot of the first two principal components of PLFAs extracted from each sample. Points show mean coordinates of treatment replicates, bars show standard errors $(n=5)$; (b) loading plot in which the PLFAs which contribute most to the discrimination between treatments are labelled; (c) $\delta^{13} \mathrm{C}$ profiles of the three PLFAs the contributed 
most to the discrimination observed between treatments. Larger bars represent more uptake of applied enriched ${ }^{13} \mathrm{C}$ material. Columns show means. Bars show \pm standard errors $(n=5)$. 
Table 1. Key Biochar and Feedstock characteristics

\begin{tabular}{|c|c|c|}
\hline & Biochar & Residue \\
\hline Fixed Carbon (\%) & 36.3 & 14.1 \\
\hline Volatiles (\%) & 32.9 & 71.4 \\
\hline Nitrogen (\%) & 2.7 & 2.3 \\
\hline Hydrogen (\%) & 3.4 & NA \\
\hline $\mathrm{C}: \mathrm{N}$ ratio & 22.0 & 31.9 \\
\hline Sulphur (\%) & 0.4 & NA \\
\hline $\mathrm{H}: \mathrm{C}_{\text {org }}$ & 0.59 & NA \\
\hline Ash (\%) & 28.0 & 9.6 \\
\hline $\mathrm{pH}$ & 9.2 & 5.4 \\
\hline${ }^{13} \mathrm{C}$ enrichment & $1.38 \pm 0.0002$ at- $\%$ & $1.40 \pm 0.003$ at $-\%$ \\
\hline${ }^{15} \mathrm{~N}$ enrichment & $58.2 \pm 0.01$ at $-\%$ & $58.5 \pm 0.03$ at- $\%$ \\
\hline
\end{tabular}

(All values provided on an oven dried $\left(60^{\circ} \mathrm{C}\right.$ ) basis. $\mathrm{pH}$ was quantified in demineralised water 1:5 w/v) 
Table 2: Key soil characteristics (based on soil dry weight)

\begin{tabular}{|c|c|}
\hline Soil Texture & \\
\hline Sand (\%) & 93.9 \\
\hline Silt (\%) & 4.3 \\
\hline Clay (\%) & 1.8 \\
\hline $\mathrm{pH}\left(\mathrm{CaCl}_{2}\right)$ & 5.2 \\
\hline SOM (\%) & 4.6 \\
\hline $\mathrm{N}$-content $\left(\mathrm{mg} \mathrm{kg}^{-1}\right)$ & \\
\hline $\mathrm{N}-\mathrm{NH}_{4}$ & $1.51 \pm 0.19$ \\
\hline $\mathrm{N}-\mathrm{NO}_{3}$ & $0.97 \pm 0.07$ \\
\hline P-content $\left(\mathrm{mg} \mathrm{kg}^{-1}\right)$ & \\
\hline $\mathrm{P}-\mathrm{PO}_{4}$ & $3.96 \pm 0.17$ \\
\hline K-content $\left(\mathrm{mg} \mathrm{kg}^{-1}\right)$ & $16.49 \pm 0.92$ \\
\hline
\end{tabular}

